\title{
Nuevos datos biográficos sobre el compositor Antonio Ugena, maestro de la Real Capilla de Madrid (1745-1817)
}

\author{
New biographical data on the composer Antonio Ugena, master of the Royal \\ Chapel of Madrid (1745-1817)
}

\author{
José Luis de la Fuente Charfolé \\ Universidad de Castilla-La Mancha \\ Centro de Investigación y Documentación Musical-Unidad Asociada al CSIC \\ joseluis.fuente@uclm.es \\ ORCID iD: https://orcid.org/0000-0002-7167-2176
}

\section{RESUMEN}

Una buena parte de las biografías de maestros de capilla hispánicos se encuentran en constante estado de revisión y perfeccionamiento. La localización del acta bautismal del maestro de la Real Capilla madrileña, Antonio Ugena, viene a corregir los datos conocidos derivados de una lectura errónea de fuentes.

Palabras clave: Maestros de capilla, Catedral, Real Capilla.

\section{Abstract}

A good part of the biographies concerning Hispanic chapel masters are constantly in a state of revision and improvement. The location of the baptismal record of the master of the Royal Chapel of Madrid, Antonio Ugena, corrects the known data, derived from a misreading of sources.

Key Words: Chapel Masters, Cathedral, Royal Chapel. 


\section{NUEVOS DATOS BIOGRÁFICOS SOBRE EL COMPOSITOR ANTONIO UGENA, MAESTRO DE LA REAL CAPILLA DE MADRID (1745-1817)}

Fuente Charfolé, J. L. de la. (2021). Nuevos datos biográficos sobre el compositor Antonio Ugena, maestro de la Real Capilla de Madrid (1745-1817). Cuadernos de Investigación Musical, (13), pp. 16-24.

\section{INTRODUCCIÓN}

Antonio Ugena se encuentra hoy, junto a otros compositores, en el último cuartil del ranking de celebridades del siglo XVIII. Es posiblemente el único maestro de la Real Capilla que carece de perfil biográfico en la internacional Grove Music Online. La imagen que la historiografía nos proporciona de él es la de un músico incompetente, censurado por sus superiores, y responsable del declive sufrido por las dos instituciones musicales, tal vez las más prestigiosas de nuestro país, en las que se mantuvo activo durante cuarenta y siete años: el Real Colegio de Santa Bárbara y la Real Capilla de Madrid.

En relación con el estado de la investigación sobre dicho maestro hemos encontrado escasas y contradictorias posturas, la mayoría lesivas hacia su figura, juzgando la obra en función de la vida y viceversa, como si fueran entes indisociables; sólo una mínima parte se muestra más objetiva y centrada en la documentación. En general, todas evitan abordar el trasfondo del lenguaje técnico del compositor, tal vez pensando que los resultados serían tan deslucidos como el menoscabo heredado.

Saldoni aporta las primeras noticias biográficas del maestro Ugena. Inicialmente lo cita como testamentario del fagotista de la Real Capilla, Mateo Soler, hermano del padre Antonio Soler (Saldoni, 1881, p. 141); después, en una escueta nota biográfica en la que el autor evidencia el desconocimiento casi absoluto que existía a finales del siglo XVIII del maestro y su obra:

Ugena, presbítero, D. Antonio: maestro de la R. C. antes de 1787, y falleció, al parecer, en 1804, y otros suponen que en 1785. En el archivo de la R. C. hay algunas obras de Ugena, que fue sucesor en dicho magisterio de D. Francisco Courselles (Saldoni, 1881, p. 350).

Las primeras décadas del siglo XX no fueron mejores para la investigación y avance del conocimiento sobre el compositor. Al escaso interés y al abandono persistente se unió la acción inicua de poderosos musicógrafos, como Rafael Mitjana, que impulsó hacia el exterior una imagen impropia del maestro, no tanto por los comentarios excesivos y acerados como por haberse arrogado la prerrogativa de dar por juzgada una vida entera de dedicación profesional sin mediar el aval de la prueba ni más proceso crítico que sus propias conjeturas: 


\section{JosÉ LuIS DE LA FuENTE CHARFOLÉ}

Para colmo de desgracias, a la muerte de Corselli, en 1778, el puesto de maestro de capilla recayó en un tal don Antonio Ugena, que lo conservó hasta 1805. En modo alguno merecía Ugena tan gran honor ya que las composiciones que nos ha legado son insignificantes y sólo muestran un pensamiento rutinario. En tales manos el magisterio de la corte cayó de nuevo en la decadencia de la que apenas acababa de salir. Desde entonces la corte arrastró un quehacer apático, sin alcanzar el grado de esplendor que tuvo en el pasado (Mitjana, 1920, p. 2148).

Dichas afirmaciones fueron asumidas ex auctoritate por sus seguidores, y también por algún que otro autor extranjero venido a España más en busca de genios, tonadillas y zarzuelas que por el interés de remendar el roído mapa de nuestra historia musical. En este escenario no pueden sorprender afirmaciones como las que realizó Mary Neal Hamilton en relación con Teixidor y Ugena, a los que no duda en calificar de músicos "mediocres" e "insignificantes"; naturalmente el peor parado fue Ugena, prácticamente reducido a la nada, aunque tampoco se libró de la guadaña Francisco Corselli que acabó degradado a "director de tercera”. Así lo dejó expresado esta autora en su publicación de 1937, apenas iniciado el conflicto civil:

Había indiscutibles signos de decadencia en la música de la Real Capilla tras la muerte de Nebra en 1768. Como primer organista, le sucedió José Lidón, un auténtico artista; sin embargo, como vicemaestro de capilla, su plaza fue ocupada por Francisco Teixidor, un músico mediocre. Cuando Corselli falleció en 1778, un músico español insignificante, Antonio de Ugena, fue nombrado maestro de capilla demostrando ser infructuoso e indigno para suceder incluso a un director de tercera como Corselli (Hamilton, 1937. Apud. López Ruiz, 2017, p. 231)¹.

En el otro extremo encontramos el estudio de Guy Bourligueux en relación con el ingreso en la Real Capilla de Mateo Soler, en 1780. Este autor ofrece un panorama artístico totalmente opuesto, muy alejado de la visión decadentista ofrecida por Mitjana y sus seguidores:

Convendría sin duda evocar -por lo menos rápidamente- el magnífico ambiente artístico-musical de la Corte borbónica de los Reyes Carlos III y Carlos IV, ambiente en el cual se movió nuestro instrumentista, mientras que su hermano Fray Antonio vivía los últimos años de su existencia en el Monasterio de San Lorenzo de El Escorial (Bourligueux, 1985, p. 85).

\footnotetext{
${ }^{1}$ Cabe adelantar la primicia de una próxima edición de la obra en latín del discípulo de José Lidón, el compositor asturiano Ramón Garay. Véase Capdepón, 2016.
} 


\section{NUEVOS DATOS BIOGRÁFICOS SOBRE EL COMPOSITOR ANTONIO UGENA, MAESTRO DE LA REAL CAPILlA DE MADRID (1745-1817)}

Como nada es simple, y aún menos el funcionamiento de una Real Capilla, el estado debería oscilar entre una y otra postura, estimación que no quedará fijada hasta que la documentación sea absolutamente desbrozada y valorada. Sólo a partir de las evidencias se podrán obtener respuestas ajustadas a las múltiples incógnitas que rodean la biografía de tan ilustre muerto, figura en la que no se ha profundizado con la exhaustividad, rigor y respeto que habría merecido.

\section{ACTUALIDAD historiográfica SOBRE la NATURALEZA DE ANTONIO UgENA}

La publicación de algunos de los registros pertenecientes a los libros parroquiales de San Martín y San Pedro el Real de Madrid, en concreto el relativo a entierros, certificó el fallecimiento del maestro. El manuscrito también contiene el dato de la localidad en que nació Ugena: "Veles, (sic!) en Cuenca", lugar que no pertenece a dicha provincia. La nota dice así:

Ugena y Langa, Antonio: Presbítero, maestro de capilla jubilado de la Real Capilla de palacio, y rector del real colegio de Niños cantores de esta corte, natural de Veles, en Cuenca, hijo de Juan y de Teresa, murió el 29 de abril de 1817 (Parroquia de San Pedro el Real, Libro de difuntos 30, fol. 127)².

Seis años más tarde, el muy esforzado trabajo de investigación de Judith Ortega sobre la música en la Corte de Carlos III y Carlos IV, cristalizado en una tesis doctoral defendida en 2010, define un breve perfil biográfico de Antonio Ugena naturalizándolo en VélezMálaga, sin que se nos dé la razón del asentamiento malagueño en detrimento de VélezRubio, Vélez-Blanco o, incluso, Vélez de Benaudalla: "Ugena, Antonio. Nació en Vélez (Málaga), en 1745 ó 1746; falleció, ca. 1816. Maestro de la Capilla Real y compositor”" (Ortega, 2010a, p. 112). Esta autora juzgó la producción y calidad compositiva del maestro como "mediocre", achacándole además inacción e irresponsabilidad en el desempeño de su cargo:

Un signo de esta decadencia fue la sustitución del maestro de capilla Francesco Corselli, músico de altísimo nivel, por Antonio Ugena, un compositor mediocre, que no se implicó en el desempeño de las relevantes responsabilidades que le habían sido encomendadas. Posiblemente, Ugena se viera desalentado por la escasa atención que Carlos III prestaba a la música, y por la dedicación del príncipe Carlos a la música instrumental, para lo que convocaba de manera constante a los mejores músicos de la capilla a la asistencia a su cuarto. Cuando Carlos IV fue nombrado rey, no solamente empleaba en su Cámara a los mejores músicos de la orquesta de la Real Capilla, sino que incluso ofrece estas plazas a los músicos que contrataba de fuera. Llega incluso a adjudicar una plaza tan relevante como la de vicemaestro al maestro de cantar de la

\footnotetext{
2 Véase Fernández García, 2004, p. 121. 


\section{JOSÉ LUIS DE LA FUENTE CHARFOLÉ}

princesa de Asturias, Francisco Federici, vaciando de contenido a este empleo que era considerado un destino de excelencia profesional (Ortega, 2010a, p. 347-348).

Los anteriores rasgos biográficos de Ugena fueron reproducidos en el Diccionario de la música española e hispanoamericana, en la voz: "Ugena, Antonio. Vélez (Málaga), 1745 o 1746; ?, ca. 1816. Maestro de capilla. Se formó como niño de coro en el Real Colegio de Niños Cantores de Madrid donde entró en 1758" (Ortega, 2010b, p. 552). Con un formato similar volvemos a encontrarlos en la miscelánea de sonatas instrumentales a solo, estudio publicado el mismo año que los anteriores: "Antonio Ugena (Vélez, Málaga, 1745 o 1746; ¿, ca. 1816)”, en él los autores incluyen también las valoraciones que, sin aportar nada al conocimiento del músico, abundan en el deslucimiento de su memoria: "Su etapa al frente de la institución fue muy complicada, tanto por su incapacidad para la gestión de estas organizaciones, sobre todo del colegio, como por su deficiencia en la composición” (véase Ortega \& Berrocal, 2010).

El Diccionario Biográfico Electrónico de la Real Academia de la Historia repite los rasgos generales ya conocidos sobre la naturaleza veleña de Ugena, en este caso colocando entre interrogaciones la inclusión de la localidad en el obispado de Cuenca. Reitera igualmente las fechas de nacimiento y muerte, pero evita emitir valoraciones sobre la capacidad y mérito del compositor (véase Cabañas, s.f.).

El interesante artículo de Luis López Morillo, centrado en el estudio del texto de uno de los villancicos escritos por Ugena, incorpora la referencia del texto de Fernández (nombre, segundo apellido y año de fallecimiento) así como la filiación errónea del maestro: "Antonio Ugena y Langa nació en Vélez, localidad del obispado de Cuenca, hacia 1746, y falleció en Madrid en 1817', a pesar de que Vélez nunca fue una localidad del obispado de Cuenca (López Morillo, 2014, p. 125).

Llegados a 2017, Miguel Ángel Delgado también naturaliza a Ugena como veleño en su tesis sobre el maestro de la catedral de Sevilla, Domingo Arquimbau, con similar reincidencia en el equívoco, aunque en este caso se trata de un dato secundario, colateral al tema central de su investigación: "A Corselli le sucederá en el cargo Antonio Ugena, natural de Vélez-Málaga y fallecido en 1816” (Delgado Zambruno, 2017, p. 52).

Otros trabajos posteriores inciden en la reiteración. Así Luis López Ruiz, sobre los cambios estilísticos del lenguaje en las misas de la Real Capilla, donde incluye los datos de Judith Ortega y las valoraciones sobre la decadencia de esta institución musical: "Antonio Ugena y Langa nació en Vélez (Málaga) en 1745 o 1746” (López Ruiz, 2020, p. 161). También Tomás Garrido incorpora dichas referencias en su producción de Música Española para orquesta de Cuerda Siglos XVIII-XIX, en cuya contextualización aparece incorporada acríticamente la información anterior:

Antonio Ugena: Pieza para un examen de Trompa. Aparte de su nacimiento en Vélez, obispado de Cuenca, no hay datos sobre Ugena antes de su llegada a Madrid en 1758 como niño de coro para la Real Capilla donde se formó (Garrido, s.f., párr. 37). 


\title{
NUEVOS DATOS BIOGRÁFICOS SOBRE EL COMPOSITOR ANTONIO UGENA, MAESTRO DE LA REAL CAPILLA DE MADRID (1745-1817)
}

Internet es una herramienta muy valorada por su inmediatez, pero muy poco aconsejable en contextos científicos a la hora de aportar información si antes no ha sido constatada en las fuentes primarias. El acceso universal al contenido puede generar un encadenamiento diabólico de errores, valoraciones y falsedades que acaban multiplicadas de forma imparable e irreductible. En este sentido la única inclusión que aparece sobre Antonio Ugena en la inagotable y popular Wikipedia ${ }^{3}$ es efectuada en calidad de veleseño, junto a filósofos, pintores, políticos, poetas, entrenadores, futbolistas, y cantantes de operación triunfo (Reproducido en Vélez-Málaga, 2021).

\section{ACTA DE BAUtismo de ANTONio Ugena}

Los datos extraídos de la participación de Ugena en la oposición al magisterio de la catedral de Cuenca del año 1768, cuyo estudio detallado será publicado en próximas fechas, ha hecho posible la localización de su acta bautismal, documento desconocido hasta la fecha, así como el avance de su contenido en esta breve nota. El manuscrito que certifica que el maestro nació en el término de Uclés, provincia Cuenca, dice así:

\begin{abstract}
Antonio Ugena y Langa nació en la localidad conquense de Uclés el día 5 de julio de 1745 "a las diez de la noche poco más o menos", siendo bautizado en la parroquia de Santa María y San Andrés por el entonces cura propio, don Domingo Echevarría, el día 10 de julio de dicho año. Sus padres fueron Juan de la Cruz Ugena y Teresa de Langa, también naturales de Uclés; Antonio fue apadrinado por su hermano, José de Ugena, tal y como se consigna en dicha acta (Uclés, Iglesia parroquial de Santa María y San Andrés Libro de Bautismos 5/1, fol. 5v.) $)^{5}$.
\end{abstract}

\footnotetext{
3 Vélez-Málaga (06 de junio 2021). Wikipedia. Recuperado de https://ca.wikipedia.org/w/index.php?title $=\mathrm{V} \% \mathrm{C} 3 \% \mathrm{~A} 9 \mathrm{lez}-\mathrm{M} \% \mathrm{C} 3 \%$ A1laga\&oldid $=27402406$

4 [Marginal izquierdo: Antonio hijo de Juan de la Cruz Ugena, y de Theresa de Langa] En la iglesia parroquial de Sta. Maria y S. Andres de la villa de Ucles en diez de julio de mil setecientos y quarenta y cinco años. Yo D. Domingo Chavarría cura propio de dicha parroquial Bautize y Chrisme solemnemente a un niño que nació el dia cinco de dicho mes a las diez de la noche poco más o menos, hijo legítimo de Juan de la Cruz Ugena, y de Theresa de Langa vecinos y naturales de esta dicha villa: le puse por nombre Antonio; fue su padrino Joseph de Ugena su hermano, a quien adverti la obligación que habia contraido, y para que conste lo firme ut supra. D. Domingo Chavarría.

5 Agradezco al reverendo padre don Pedro Medina Balaguer, párroco de la localidad de Uclés, el haberme facilitado el acceso a la documentación de su archivo parroquial, y a doña Ana María Gálvez, gerente y encargada de dicho fondo, por su eficaz e impagable colaboración gracias a la cual, y pese a las dificultades derivadas de las restricciones sanitarias sufridas, la comunidad científica recibe hoy esta información.
} 


\section{José LuIS DE LA FUENTE CHARFOLÉ}

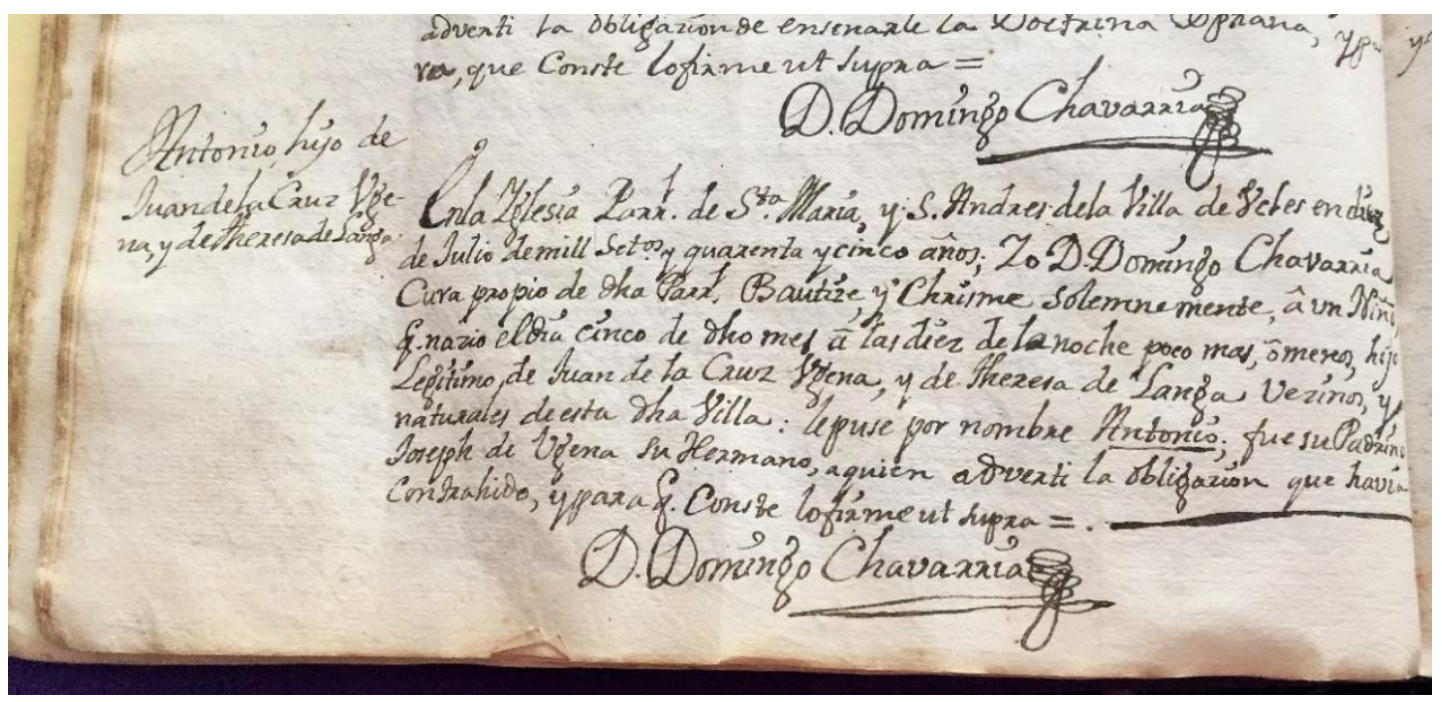

Fig. 1: Acta de bautismo de Antonio Ugena.

(Uclés, Iglesia parroquial de Santa María y San Andrés Libro de Bautismos 5/1, fol. 5v.)

La asignación errónea de la naturaleza malagueño-velesina en lugar de la conquenseucleseña procede posiblemente de una lectura defectuosa del manuscrito de Hergueta, descuido que acabó reproducido y amplificado en cadena (véase Hergueta, 1898). Cabe recordar que en el siglo XVIII la letra "u" mantenía la doble función como vocal y consonante. En la práctica documental y libraria el grafo "u”, cuando era inicial o versal, era escrito como V; por ello, el actual "Uclés" aparece como "Vcles" en el manuscrito parroquial y otros lugares. A esta singularidad se unió el parecido de la "c" con la "e", detalle que consumó la confusión de "Vcles" con "Veles", y la reconversión posterior en "Vélez" con el aditamento "Málaga", actualización que cerró el círculo y consolidó el equívoco.

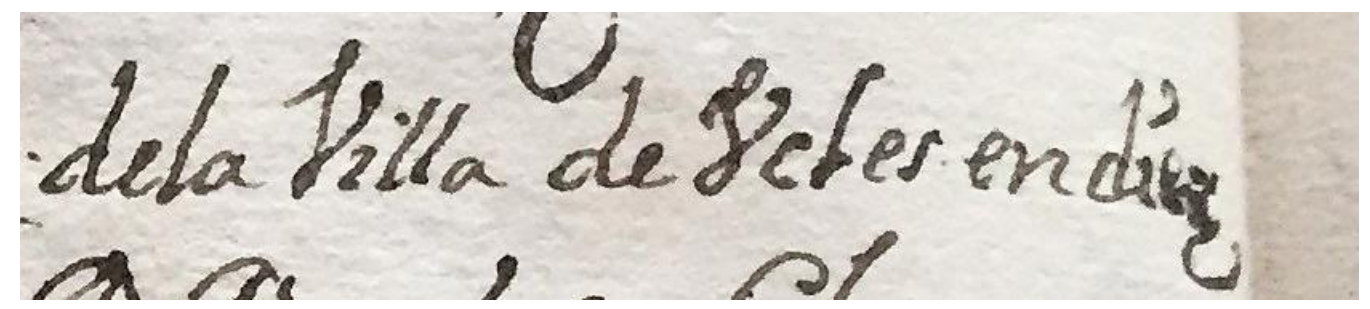

Fig. 2: Ejemplo del uso manuscrito de la "u/v" inicial en "Villa", "Vcles" (Uclés).

Acta de bautismo, detalle.

(Uclés, Iglesia parroquial de Santa María y San Andrés Libro de Bautismos 5/1, fol. 5v.) 


\section{NUEVOS DATOS BIOGRÁFICOS SOBRE EL COMPOSITOR ANTONIO UGENA,} MAESTRO DE LA REAL CAPILla DE MADRID (1745-1817)

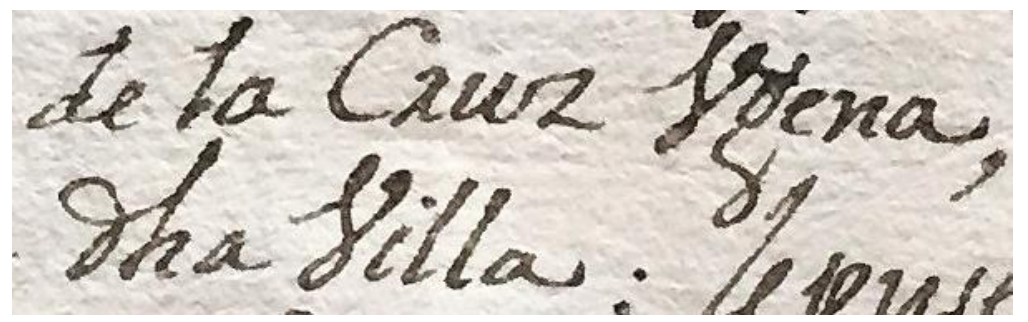

Fig. 3: Ídem en "Villa" y "Vgena" (Ugena). Acta de bautismo, detalle

(Uclés, Iglesia parroquial de Santa María y San Andrés Libro de Bautismos 5/1, fol. 5v.)

\section{CoNCLUSIÓN}

No son las breves líneas de esta nota el espacio adecuado para mayor profundidad biográfica sobre el maestro de capilla Antonio Ugena, elementos que nos reservamos para una próxima aportación. El propósito no ha sido otro que avanzar el contenido del acta bautismal localizada, hasta el momento desconocida, dejando constancia fehaciente de los datos sobre la naturaleza y fecha de nacimiento de este maestro a la espera de que todo ello sea convenientemente citado en las investigaciones presentes y futuras.

\section{BIBLIOGRAFÍA}

Bourligueux, G. (1985). Un hermano del padre Antonio Soler, fagotista de la Real Capilla madrileña. Revista de Musicología, 8(1), pp. 83-95.

Cabañas Alamán, F. (s.f.). Ugena, Antonio. Vélez, ¿Cuenca?, s. XVIII - c. 1816. Maestro de capilla y compositor. En Diccionario Biográfico electrónico. Madrid: Real Academia de la Historia. Recuperado de http://dbe.rah.es/biografias/30420/antonio-ugena.

Campos y Fernández de Sevilla, Javier. (1987). Una Hermandad religiosa en la Ilustración española: La Congregación de Santo Tomás de Villanueva de Madrid. Revista Agustiniana, 28, pp. 167-243.

Capdepón Verdú, P. (2016). El compositor asturiano Ramón Garay (1761-1823). Biografía y estudio de su obra musical. Madrid: Fundación María Cristina Masaveu Peterson.

Delgado Zambruno, M. A. (2017). Estudio sistemático y cualitativo de oboe en la obra de Domingo Arquimbau durante su magisterio en la Catedral de Sevilla (1790-1829): su inserción en las Programaciones para Conservatorios. (Tesis Doctoral). Sevilla: Universidad de Sevilla.

Fernández García, M. (2004). Parroquias madrileñas de San Martín y San Pedro el Real. Algunos personajes de su archivo. Madrid: Caparrós Editores. 


\section{José LUIS DE LA FUENTE CHARFOLÉ}

Garrido, T. (s.f.). Música Española para Orquesta de cuerda Siglos XVIII-XIX. En Tomás Garrido. Recuperado de http://www.tomasgarrido.es/Musica_espanola_orq._cuerda.html

Hamilton, M. N. (1937). Music in eighteenth century Spain. Urbana: Universidad de Illinois.

Hergueta, N. (1898). Profesores músicos de la Real Capilla de S. M. según documentos de su archivo. (Manuscrito). Loyola: Archivo y Biblioteca Musicales Padre Otaño.

López Morillo, L. (2014). Mirad nuestra Princesa... Una lectura política del villancico de Inocentes Alerta, moradores de Belén de Antonio Ugena en la Capilla Real de Carlos II. Cuadernos de Música Iberoamericana, 27, pp. 103-129.

López Ruiz, L. (2017). El compositor José Lidón (1748-1827): obra teórica y análisis de su música liturgica. (Tesis doctoral). Madrid: Universidad Complutense de Madrid.

López Ruiz, L. (2020). Transformaciones estilísticas en las misas de la Real Capilla de Madrid entre 1778 y 1833. Revista de Musicología, 43(1), pp. 155-192.

Mitjana, R. (1920). La musique en Espagne. Art religieux et art profane. En A. Lavignac y L. de La Laurencie (Eds.). Encyclopédie de la musique et dictionnaire du Conservatoire, vol. 4 (pp. 1913-2351). París: Delagrave.

Ortega Rodríguez, J. (2010a). La música en la Corte de Carlos III y Carlos IV (1759-1808): de la Real Capilla a la Real Cámara. (Tesis Doctoral). Madrid: Universidad Complutense de Madrid.

Ortega Rodríguez, J. (2010b). Ugena, Antonio. En E. Casares (Dir. y Coord.) Diccionario de la música española e hispanoamericana, vol 10 (pp. 552-555). Madrid: SGAE.

Ortega, J. \& Berrocal, J. (2010). Sonatas a solo en la Real Capilla (1760-1819). Madrid: Instituto Complutense de Ciencias Musicales.

Saldoni, B. (1881) Diccionario Biográfico-bibliográfico de efemérides de músicos españoles (tomo III). Madrid: Imp. A. Pérez Dubrill.

Fecha de recepción: 07/01/2021

Fecha de aceptación: 24/03/2021 